\title{
Overcoming barriers of isolation in Distance Learning: Building a Collaborative Community in Learning
}

\author{
Nchindo Richardson Mbukusa \\ Faculty of Education, University of Namibia \\ Windhoek, Namibia \\ Dan Kibuule \\ Head of Department \\ Pharmacy Practice and Policy Department \\ School of Pharmacy, University Of Namibia. \\ Jennie Lates \\ Head of Department, School of Pharmacy \\ University of Namibia.
}

\begin{abstract}
The rise in popularity of distance education programmes in a rural and remote Namibia poses challenges on students that are far removed from their colleagues, tutors and even their study materials. Interaction between the student and the study materials, tutors and peers are key challenges in open and distance learning. At the same time, sparsely populated areas of the country with less network coverage pose more challenges for web-based learning that could close up the gap. Using interviews, supported by this study engaged 5 groups of students (eight in each group) who have initiated collaborative groups while doing research studies at the Centre for External Studies, University of Namibia. The students are continuing with their educational endeavours through open and distance learning but who find themselves in areas that isolate them more from academic, administrative and logistics support. Their experiences of distance learning were investigated and three main themes emerged. These were academic and administrative challenges. Amongst many, the recommendations included: improving student-study materials contact, student-tutor contact and student-student contact (collaborative learning). Students do well when there is clear support from peers, tutors and the study materials that they interact with from day to day.
\end{abstract}

Key words: Open and Distance Learning, Isolation, Interaction, Collaborative Learning

\section{THE CONTEXT OF DISTANCE LEARNING AT THE UNIVERSITY OF NAMIBIA}

Studying through distance education has its own challenges and opportunities. The Centre for External Studies at the University of Namibia (CES-UNAM) has a student population of about 4000 learning through the distance education mode. More than half of this population is in the rural and remote areas where students have no internet connectivity. Because of the vastness of the country, schools are far away from one another and as a result of public transport that is rarely existent; students find it difficult to connect with their colleagues doing the same programmes.

The CES-UNAM still reaches its students through the printed materials, where students receive a package of study materials during registration times, completes the enclosed assignments and return them via the regional centres that will post to the main campus where tutors will 
mark and return the feedback to the students. The tutors and students are separated spatially and by time (Liu, 2008). More recently there are a few who are learning through the social media platforms and other forms of e-learning. The University has however introduced the UNAM portal where students can download study hints, view assessment results and their financial statements. Beyond that, the e-learning is underdeveloped at the University. There is therefore a strong need for building collaboration among students despite the barrier of isolation that students face each day. Interesting enough, despite the situation above, there are some students that are doing very well in such isolated areas. A high number of students in similar areas are not doing well. This study seeks to find out why such discrepancies exist and the possible solution as per the perceptions of the students. This study therefore investigated the opportunities that distance education students have developed on their own through collaborative learning despite the barrier of isolation.

\section{Isolation in Distance Education}

\section{THEORETICAL FRAMEWORKS}

For several decades, writers such as Wedemeyer (1971) and Moore (1983) have critically assessed adult distance learners on their ability to independently study. Wedemeyer focused on distance education in terms of the autonomy of the learner, distance between the teacher and the learner and the situational system. Bates (1995) opined that distance education students engage the largest part of their studies alone by either interacting with the textbooks or other learning materials. The more distance education learners lack academic and administrative support, the more they feel isolated from the institution, colleagues and other resources that need to guide them during their studies (Mbukusa, 2010).

Isolation therefore can be overcome by ensuring that there is more and frequent communication to students. Keegan (1986) believes that the separation of student and teacher imposed by distance removes a vital "link" of communication between these two parties. The link must be restored through overt institutional efforts so that the teaching-learning transaction may be "reintegrated" (Keegan, 1986, p. 120). Gilbert and Moore (1998) describe two contexts of interaction: the 'social interaction' between two or more people about the learning material; and the 'instructional interaction' between the individual and the learning material. When these are maximized, students find it easier to complete their studies. Student motivation is another building block to subverting isolation (Verduin and Clark (1991). Citing Tinto (1975), Keegan hypothesized that students who did not receive adequate reintegration measures such as electronic or telephone communication, would be less likely to experience complete academic and social integration into institutional life. Consequently, such students would be more likely to drop out (Sheets, 1992).

Galusha (1998) noticed that "problems and barriers encountered by the student fall into several distinct categories; costs and motivators, feedback and teacher contact, student support and services, alienation and isolation, lack of experience, and training." This study only focused on isolation.

\section{Collaboration as a building block to isolation}

New theories of learning that have emerged and developed during the last decades have pointed out to the social dimension of learning processes. Amongst many, theories such as Distributed cognition theory (Hutchins, 1991; Hollan, Hutchins \& Kirsh, 2000), Activity Theory (Jonassen, 2000) and Situated Learning (Resnick et all., 1991; Clancey, 1997; Greeno et all, 1993) have had a significant impact on how important collaborative learning is to students that far away from one another. Institutions that have advanced with technology-based learning have developed several ways on how to support students that collaborate online. Computer- 
Supported Collaborative Learning (CSCL) has been designed and numerous students around the globe are benefiting from its use (Koschmann, 1999).

Dillenbourg P. (1999) defines collaborative learning as "a situation in which two or more people learn or attempt to learn something together." He goes on to define each element of his definition in several interpretations. He says

- "two or more" may be interpreted as a pair, a small group (3-5 subjects), a class (20-30 subjects), a community (a few hundreds or thousands of people), a society (several thousands or millions of people)... and all intermediate levels.

- "learn something" may be interpreted as "follow a course", "study course material", "perform learning activities such as problem solving", "learn from lifelong work practice"

- "together" may be interpreted as different forms of interaction: face-to-face or computer mediated, synchronous or not, frequent in time or not, whether it is a truly joint effort or whether the labour is divided in a systematic way

This study defines collaboration in the same manner despite the fact that it concentrates on students who collaborate with less technology. These are students that may collaborate synchronously and asynchronously for one or two hours, in groups or pairs, depending on circumstances surrounding their learning environments in order to solve their learning problems. They may use their smartphones, electronic mail or physically come together at a place where learning can take place.

\section{Purpose of collaboration}

The purpose of collaboration is to promote learning during users activities. It enables to exchange ideas or information or materials that are meant to facilitate learning and assure completion of the programme. Most of the integrated systems for distance education, offers tools to communicate and exchange but not really to collaborate (Dimitracopoulou \& Petrou, 2003).

\section{CHALLENGES FOR DISTANCE LEARNING}

There are several barriers associated with online collaborative learning. Amongst many, the delivery of course programmes is a significant challenge for distance learning (Fry, Ketteridge, \& Marshall, 2003). The student may experience difficulties in undertaking their own knowledge construction (Alexander, 2001). It is difficult to encouraging participation (Gibson, Tesone, \& Blackwell, 2001) and as a result students become anxious in their learning (Hughes and Daykin, 2002). According to Connolly, Jones, \& O'Shea (2005, p.66), 'developing appropriate materials is a major challenge' for distance learning.

The diversity in student type makes it a key challenge (Connolly et al., 2005; Lorenzetti, 2005; and Lake, 1999), as students in higher education use a wide variety of learning styles.

Motivation is the most important factor for effective learning according to Rogers (2001); Rovai, Ponton, Wighting, \& Baker (2007), and Whiting, Liu \& Rovai, (2008). Traditional students are more likely to be extrinsically (externally) motivated whereas distance learners tend to be intrinsically (independently) motivated (Whiting et al., 2008).

They are also likely to recognise professional rewards from their education (increased salary, more responsibility, better job prospects and the related) (Rogers, 2001) or they fear to repay course fees to their employers. 
Studying alone can be time-consuming and consequently requires heightened levels of motivation. Self-discipline, careful planning (Liu, 2008) and time management (Alexander, 2001) are skills that need to be demonstrated by a distance education learner.

(Park, 2008, p.16) found distance learning students mentioning 'the risk of feeling isolated' (Ipsos MORI, 2007). There is also the likelihood of psychological isolation resulting from the physical and temporal isolation experienced by learning at a distance (Lake, 1999; Wegner et al. (1999); Rovai (2001); Dickey (2004); Lorenzetti (2005); and Stodel et al. (2006). Isolation could be typified by time (concurrent study); space (geographic dispersal); social (awareness of others), intellectual/experience (academic ability and life experiences); profession (subject related expertise); ICT knowledge; sensory (ability to see/feel/hear peers); cultural; and subject (if anyone else is studying the same topic). Students' individual learning style and motivation for studying may affect their willingness and need to interact with others (Liu, 2008), and therefore their experiences of isolation.

The rise in popularity of social networking and other web-based technologies suggests that there is need to introduce such opportunities for the distance learning programmes at CES, UNAM in order to overcome students' feelings of isolation. Gaining further knowledge about the experiences of students on distance learning courses, and their perceptions of weblearning environments, will be necessary to advance this debate (Dickey, 2004). The purpose of this study therefore is to find out how barriers of isolation in distance learning could be removed using collaborative learning. The study focuses on students that are in remote areas where technology is less used for learning purposes.

\section{PURPOSE OF THE STUDY}

The research question addressed is: 'How can student learning experiences on a non-campus based programme, in the absence of online collaboration, be enriched through reducing the potential for isolation?' Three sub-questions are generated from this:

$>$-What are the experiences of students on isolation and collaboration?

$>$-What are the barriers and challenges to improving the learning experiences for such students?

$>$-What solutions could be used to overcome these barriers and challenges?

\section{RESEARCH METHODOLOGY}

This study followed a qualitative research methodology supported by an initial survey results. The researcher engaged 5 groups of students (eight in each group) who have initiated collaborative groups while doing research studies. Three of the students that did well in their studies, were followed through open interviews (one on one) on several occasions over a period of time in a year to find out how they managed to collaborate and break isolation. The other two that performed poorly were also conveniently followed on face to face interviews. These are students that are in remote areas where electricity is not existent but are able to use their smartphones and can meet together during the periods of time when they go to a central place for shopping.

A survey was done prior to the qualitative engagement through a questionnaire (see appendix $A$ ) to gather the initial findings from 50 students. Through that, the researcher easily sampled out the information-rich and extreme deviant cases for qualitative studies using an interview guide (Patton, 1996, pp. 169-186). Field notes (Lofland, \& Lofland, 1984) strengthened the collection of data. The findings from the students' voices were captured, narrated and analysed using summaries under identified themes. 


\section{DISCUSSION AND ANALYSIS OF FINDINGS}

The findings of the study were drawn from the interview guide research questions of the study and the following themes were developed:

\section{Academic barriers \\ Remoteness and ruralness}

One of the major findings of the study is the unavailability of electricity and in some cases connectivity of internet for students to 'switch to online learning' (Student A). When the student was asked about her experience of isolation in relation to her studies she had this to say: "We hear about other students in other countries learning through social media and other platforms. We have our Unam Portal but we do not get what we want from it at maximum. We wish the paper materials are done away with. We have smartphones that can connect us to the outside world".

\section{Isolation and connectivity}

As learnt from (Lake, 1999; Wegner et al. (1999); Barrett and Lally (2000); Hartley et al. (2001); Rovai (2001); Dickey (2004); Lorenzetti (2005); and Stodel et al. (2006) students have showed that psychological feelings of isolation may arise from the geographical separation, lack of timeg and contact with fellow students. Student B retorted that "I am about $100 \mathrm{~km}$ form the nearest student doing the same programme with me. We cannot easily meet unless if we meet at the end of a month when we go shopping. This is the time we can arrange with the Teachers Resource Centre for us to meet and discuss our lessons."

Asked if there is an expert of the subject matter that would lead the discussions when they meet, Student $\boldsymbol{C}$ said "There is no expert to talk to or guide us so we have to phone our lecturers to give us answers in time before we meet."

One of the strength of collaborative learning is that students initiate their own ways of coping with isolation. Group A were asked to share how their group started. "We have found selfstudy groups very interesting. In the first place, we were not told to form up groups where we can discuss our problems. We just decided to come together because we have seen that we score more marks by sharing ideas." When later probed on plagiarism, the group continued saying that "We do not write the same thing at the end of the day but at least we inspire one another. We have learnt from other modules that copying from each other make us lose marks. We can also be subjected to discipline that could force us from the University".

The issue of time management came out quite strong. Group B shared on how they manage their time during collaborative learning. "We agree on how long we will share or discuss the lesson that we have identified as problematic and then that is what we discuss."

"In the absence of the library where we work we use our smartphones when we are in connected areas. We google up some topics and we take notes from there. We have been guided by our research lecturer on how to google topics and this has been of great use to us. It is difficult to use the google web as sometimes there are no printers that are wireless so that one could print. We still have very basic smartphones and basic printers" (Student D).

\section{Tutor contact}

Students were asked on how much contact stands between them and their tutors. It was found that distance education tutors take long to talk to the students. Students cited factors such as poor network and the distance of the country as major reasons for not talking to their tutors regularly. They postulated that this could be the reason tutors do not talk to them regularly as 
well. This poor communication between tutors and students cause more isolation to students. Asked if there was need for this communication to exist, students felt that the need is there as it helps them feel that they are supported by the institution and the system that runs their affairs.

The 'presence' of the tutor in any form help student's 'build up a relationship' as knowing that someone was available in times of need bridged the gap of being isolated by the institution and other systems that are meant to support the student.

\section{Interaction with peers and colleagues}

The study found that students' experience of contacting other students was extremely limited. Interesting enough, there are two students who showed that they would not mind studying alone. This case was not followed up as the interest of the study focused on the students that felt the isolation and needed collaborative learning.

Group A saw interaction with other students as being a being crucial to the completion of their programmes. What they regretted most is the absence of a system that supports their 'own efforts of collaborating.' "it is clear that the University has no online support for us. But for how long will this be?" asked a seemingly disgruntled Student A. Support from work colleagues during studies was also investigated and found that there are no mentors in schools within their areas of specialisation. The gap that stands between the Basic Education Teachers Diploma and the Bachelor of Education content is too wide for the other colleagues at work to support students. There are other colleagues who are doing Bachelor of Education with other institutions in the country but there still stands a clear difference in the content that is offered by the University of Namibia. Students enrolled for the Bachelor of Education with CES, UNAM are therefore forced to find where the other colleagues are and begin a collaborative effort.

\section{Motivation and self-discipline}

The irregular contact with other students, colleagues at work and tutors to maintain momentum demotivates students. Students cannot meet deadlines for the submission of assignments and projects. Sometimes, as a result of distance and failure to learn from sources when the results are due and the writing of examinations dates make them miss it all. They place this difficult on the fact that they are isolated from one another and where teaching and learning activities take place.

\section{Online communities}

The study also investigated to find out whether students used their smartphones for social networking. Out of the 50 students that responded to the question, 37 showed that they use their smartphones for browsing Facebook, Twitter, LinkedIn and other social media almost every time when there is clearer connectivity. Student $F$ showed that he usually collaborates with other students using Facebook and Twitter. They have created their own page for helping one another. The student said he has learnt this application from friends using the media for other reasons.

\section{Administration barriers}

Students were also asked to share on the study materials and their delivery. Student E took interest in this and mentioned that "I find it strange that we still receive study materials. We should now be give opportunities to choose between hard copies and online materials. I have seen friends from other institutions that learn through their computers. CES should provide computers to us so that we learn via that way". 
Group D mentioned that "the materials should help me do the work alone. Maybe they should write materials in a way that they know I am alone and I may not find friends to work with".

\section{Overcoming barriers of isolation}

Students were asked to suggest ways on how to ensure that despite the isolation that exist, some improvements could still be made. The following are their suggestions as confirming what most literature suggest.

One that is key to placement in remote areas is for the government to hasten the connection of wireless hubs and proper infrastructure establishments. There is no "excuse to run away from these areas as our brothers and sisters are studying here. The government should just know that we are here and we need services for our studies".

Contact between students and tutors should be improved. Their instructions should be simple, clear and to the point "so that we do not suffer to find answers. Be practical in the way that study materials are written such that friends, when asked, can easily help us". Students should be encouraged to form up self-study groups while waiting for e-learning platforms. There is more that they can learn from one another. There is also need for the university to provide maps of where all students doing the same programmes are found. Their contacts, if made available to all students will add value to collaborative learning.

In terms of preference for improvements to distance learning programmes, students emphasised the following in their groups:

- CES should improve tutor-student contact

- Continue working in groups as they offer friendliness than the way tutors would do.

- Tips and comments from each group on how to collaborate should be posted

\section{CONCLUSIONS AND RECOMMENDATIONS}

Collaborative learning has many benefits to students and the institutions. Amongst man, students actively exchange, debate and negotiate ideas within their groups to increase interest in learning. They retain the information longer and also appear more satisfied with their classes. Collaborative learning builds self-esteem in students and thus helps them complete their studies in time. Their critical thinking skills increase and their retention of information and interest in the subject matter improves As much as it is the responsibility of the government to connect all parts of the country; it is still common that there are isolated students as a result of infrastructure, time and geographical placement of students. Isolation is still an issue in distance education despite the advent of CSCL. There are many factors associated with it that need further studies in order to help students complete their studies with assurance.

In the absence of e-learning platforms, CES, UNAM should continue to support students in academic and administrative services as to motivate them to continue with their studies. The study materials should be written in a way as to help students commence their studies wherever they may themselves in such a remote and rural country.

There is need to investigate the experiences of tutors on isolation of students and what they propose would arrest the situation. CES, UNAM needs to seriously develop online materials deliver and support to students in the country irrespective of the connectivity that is delayed. Students who have opportunities to engage the social media will influence the few that is still behind with modern technology. 


\section{References}

Alexander, S. (2001). E-learning developments and experiences. Education and Training, 43 (4/5), 240-248

Bates, T. (1995). Technology: Open learning and distance education. New York: Routledge.

Clancey, W. J. (1997). Situated Cognition: On human knowledge and computer representations. Cambridge: Cambridge University Press

Connolly, M., Jones, N. \& O’Shea, J. (2005). Quality assurance and e-learning: Reflections from the front line. Quality in Higher Education, 11 (1), 59-67.

Dickey, M. D. (2004). The impact of web-logs (blogs) on student perceptions of isolation and alienation in a web based distance-learning environment. Open Learning, 19 (3), 279-291.

Fry, H., Ketteridge, S. \& Marshall, S. (2003). A handbook for teaching and learning in higher education - enhancing academic practice. London: Kogan Page.

Galusha, J. M. (1998). Barriers to learning in distance education. International Computing and Technology, 5 (3-4), 6-14, ERIC Reproduction Document ED 416 377. Available at http://www.nald.ca/library/research/sotfr/barrier... [Accessed 25 May 2014]

Gibson, J. W., Tesone, D. V. \& Blackwell, C. W. (2001). The journey to cyberspace: Reflections from three online business professors. SAM Advanced Management Journal, 66 (1), 30-34

Gilbert and Moore, (1998)

Greeno, J. G., Smith, D. R., \& Moore, J. L. (1993). Transfer of situated learning. In D. K. Detterman \& R. J. Sternberg (Eds.), Transfer on trial: Intelligence, cognition, and instruction (pp. 99-167). Norwood, NJ: Ablex.

Hollan J. D., Hutchins E., \& Kirsh D (2000). Distributed cognition: A new foundation for human-computer interaction research. ACM To CHI, 7(2), 174-196.

Hughes, M. \& Daykin, N. (2002). Towards constructivism: Investigating students' perceptions and learning as a result of using an online environment. Innovations in Education and Teaching International, 39 (3), $217-223$.

Hutchins, E. (1991). The social organization of distributed cognition. In L. Resnick, ed., Perspectives on Socially Shared Cognition (pp. 283-287). Washington, DC: American Psychological Association.

Ipsos MORI. (2007). Student expectations study: Key findings from online research and discussion evenings held in June 2007 for the Joint Information Systems Committee [online]. URL:

http://www.jisc.ac.uk/media/documents/publications/studentexpectations.pdf [Accessed 7 July 2014]

Jonassen, D. (2000, October). Learning as activity. Paper presented at the international meeting of the Association for Educational Communication and Technology, Denver, CO.

Keegan, D. (1986). The foundations of distance education (Second Edition). London: Routledge.

Koschmann, T. (1999). Computer support for collaboration and learning. Journal of the Learning Sciences, 8, 495497

Kuutti K. (1996) Activity theory as a potential framework for human computer interaction research. In B. A. Nardi (Ed) Context and consciousness: Activity theory and human computer interaction (pp. 17-44) Cambridge, MA: MIT Press.

Lake, D. (1999). Reducing isolation for distance students: An on-line initiative. Open Learning, 14 (3), 14-23.

Liu, S. (2008). Student interaction experiences in distance learning courses: A phenomenological study. Online Journal of Distance Learning Administration [online], 11 (1) URL:

http://www.westga.edu/ distance/ojdla/spring111/Liu111.html [Accessed 15 June 2014].

Lofland, J., \& Lofland, L.H. (1984). A guide to qualitative observation and analysis (2nd ed.). Belmont, CA:

Wadsworth.

Lorenzetti, J. P. (2005). Lessons learned about student issues in on-line learning. Distance Education Report, 9 (6), 3-4.

Mbukusa, N, (2010). Barriers to remote rural students' access of distance education support services offered by the Centre for External Studies at the University of Namibia. Pretoria: UNISA PhD Thesis (unpublished)

Moore, M. G. (1983). The individual adult learner. In M. Tight (ed.). Adult learning and education. London: Croom Helm, 153-168. 
Mbukusa, N. R., Kibuule, D., \& Lates, J. (2017). Overcoming barriers of isolation in Distance Learning: Building a Collaborative Community in Learning. Advances in Social Sciences Research Journal, 4(17) 34-42.

Park, C. (2008). The taught postgraduate student experience: Overview of a Higher Education Academy survey. York: The Higher Education Academy.

Rogers, J. (2001). Adults learning. 4th ed. Buckingham: OU Press.

Rovai, A. P. (2001). Building classroom community at a distance: A case study. Educational Technology Research and Development Journal, 49 (4), 33-48.

Rovai, A., Ponton, M., Wighting, M. \& Baker, J. (2007). A comparative analysis of student motivation in traditional classroom and e-learning courses. International Journal on E-Learning, 6 (3), 413-432.

Sheets, M. F. (1992). Characteristics of adult education students and factors which determine course completion: A Review. New Horizons in Adult education, 6(1), 3-20

Stodel, E. J., Thompson, T. L. \& MacDonald, C. J. (2006). Learners' perspectives on what is missing from online learning: Interpretations through the community of inquiry framework. The International Review of Research in Open and Distance Learning, 7(3), 1-24.

Verduin, J. R., JR. and T. A. Clark (1991). Distance Education: The Foundation of Effective Teaching (San Francisco, Jossey-Bass Publishers).

Wegner, S. B., Holloway, K. C. \& Garton, E. M. (1999). The effects of internet-based instruction on student learning. Journal of Asynchronous Learning Networks, 3 (2), 98-106.

Whiting, M. J., Liu, J., \& Rovai, A. P. (2008). Distinguishing sense of community and motivation characteristics between online and traditional college students. The Quarterly Review of Distance Education, 9 (3), $285-295$.

Dillenbourg P. (1999) What do you mean by collaborative learning? In P. Dillenbourg (Ed) Collaborative-learning: Cognitive and Computational Approaches. (pp.1-19). Oxford: Elsevier

Girbert, L \& Moore, D. R. (May-June, 1998). Building Interactivity into Web Courses: Tools for Social and Instruction. Educational Technology. p. 29-35.

Dimitracopoulou, A. \& Petrou, A. (2003). Advanced Collaborative Distance Learning Systems for young students: Design issues and current trends on new cognitive and meta-cognitive tools. Available at http://modellingspace.atosorigin.es/Documents/Collaborative/Review/adimitr/petrou/special/issue/Themes.p df. [Accessed 15 June 2014] 